\title{
ADMINISTRATIVE CAPABILITY OF LOCAL GOVERNMENT UNITS FOR PUBLIC-PRIVATE PARTNERSHIP: TOWARDS INFRASTRUCTURE DEVELOPMENT IN ZAMBOANGA PENINSULA
}

\author{
GARY A. HABIBON
}

Department of Public Works and Highways, Zamboanga City, Philippines

\section{ABSTRACT}

The primary purpose of this study is to evaluate the administrative capability of the Local Government Units (LGUs) to enable them to engage into the Public-Private Partnership (PPP) contracting scheme for major infrastructure development of Zamboanga Peninsula, Philippines since there are no PPP infrastructure projects in Zamboanga Peninsula and the public-private partnership has not been able to gain millage in this area. Specifically, the study sought to answer the following questions: (1) What is the level of administrative capability of the LGUs to implement infrastructure development projects in Zamboanga Peninsula in terms of leadership, financial resources management, and human resource management; and (2) What are the problems/constraints/challenges encountered by the LGUs in the implementation of the infrastructure projects? The study utilized qualitative design among respondents from four (4) cities and eight (8) municipalities in Zamboanga Peninsula. The data were analysed after transcribing the recorded responses of the research participants. The findings revealed that the level of administrative capability of the LGUs to implement infrastructure development projects in Zamboanga Peninsula in terms of leadership is relatively high since there were lots of projects being implemented which were materialized through the political will of the local chief executives. In terms of financial resource management, the level is also high considering that all projects in the different LGUs follow the necessary guidelines and policies on procurement, prioritization, and full disclosure among others. The Community Social Organizations (CSOs) participate in the thrust towards participatory and transparent governance in terms of budget preparation, assessment, and monitoring of projects. In terms of human resource management, the level is moderate since there were little training conducted to enhance the skills of the personnel to be part of the different infrastructure projects. On the other hand, the problems/constraints/challenges that were encountered by the LGUs in the implementation of the infrastructure projects includes the inadequate project preparation, poor project quality at entry, and poor project execution give rise to delays and changes in project scope and cost during implementation that significantly reduced the project value as well as hampered the attainment of project objectives.

KEYWORDS: LGUs; PPP; Local Government Units; Public-Private Partnership; Zamboanga Peninsula

Received: Dec 17, 2020; Accepted: Jan 07, 2021; Published: Jan 25, 2021; Paper Id.: IJCSEIERDFEB20211

\section{INTRODUCTION}

The level of administrative capability of Local Government Units (LGUs) that will enable them to engage in Public-Private Partnership (PPP) for infrastructure development in Zamboanga Peninsula is the primary target for evaluation of this study. This would resolve on the factors of leadership, financial resources management, human resources management, and the problems/constraints and challenges encountered by the LGUs in the implementation of the infrastructure projects. Flores (2013) emphasized that the significance of infrastructure for developing countries cannot be underestimated since it is regarded as the most important catalyst for economic growth, 
development and poverty reduction. Reengineering in public administration is about reinventing outworn government machinery in areas such as cost, quality, service, and speed. The concept of Public-Private Partnership initiates efficiency and ability of the government and its units to provide the mandated and inherent role of the institution for its constituency and citizenry. The level of administrative capability is the major determinant of the Local Government Units overall ability to engage in PPP projects for the infrastructure development of respective cities and municipalities in Zamboanga Peninsula.

The administrative capability of the Local Government Units within the Zamboanga Peninsula to implement Public-Private Partnership projects can be measured whether it is applicable or not within the bounds of three distinct pillars of public administration. De Guzman and Reforma (1993) identify three such requirements as dimensions of administrative capability: (1) leadership, (2) budget/financial resources management, and (3) human resource management. The facet of leadership, human resource management and financial resource management are taken into account as the bases of administrative capability. This is enclosed within the sphere of public administration as a separate and independent entity. Moreover, the system of public administration is influenced by numerous factors prevalent within government system and protocols. Most common systems follow an ideal and coherent protocol that inevitably achieves the common mission and vision of the institution. In this case, a democratized political system inherent within the status quo is influenced by ethical and moral capabilities pertinent within the given society as this contributes influential impacts within institution and government processes. Another facet that is taken into consideration connotes a decentralized administrative system that decision making processes are distributed upon local government units for further implementation and expedition of such projects. The standard projection of operational procedures in government and administrative processing takes into account the ideal goal on the development of government efficiency and effectiveness to boost the economic echelon of the society it creates.

Numerous factors are taken into consideration so as to recognize the administrative capability of the local government unit in the adoption of public-private partnership projects. Government run businesses and projects are within the jurisdiction of laws and regulations instituted by the government and agencies. In this case, such projects are bound under rules that manage and dominate the protocol and implementation of the business. Secondly, private businesses are also taken into account as such socio-cultural and attitudinal inherent behaviours among the constituency of private businesses create a wave of societal and environmental inherency within the ecosystem of business in the community. Another consideration noted in the study is the non-governmental institutions and CSO's present within the system. With this in mind, the regulation of direct and indirect government policies connotes great influence to all concerned strata with the government and the public administration ecosystem.

The administrative capability in this study refers to the strengths, potentials, and efficiency in terms of leadership, organizational structure, budgeting/financial capability, and personnel/manpower of each Local Government Units to implement a Public-Private Partnership project in their locality. It is important factor to a meaningful project initiative. It is thus necessary for implementers, the direct actors to have greater understanding and better appreciation of these administrative requirements particularly to those projects that will involve other sectors of the society such as private institutions and entities. The perception of the involved stakeholders and their experiences and insights could provide a realistic and holistic context of the administrative capability of LGUs in conducting PPPs.

The Public-Private Partnership (PPP) is collaboration between the public and private sectors, aimed at the 
implementation of projects or provision of services traditionally provided by the public sector. This cooperation is based on the assumption that each party is able to implement its own tasks that were entrusted thereto, more efficiently than the other party. In this way, the parties complement each other, dealing under PPP, right with that part of the common task they perform best. With the division of tasks, responsibilities and risks, under PPP, the most cost-effective way to create the infrastructure and delivery of public service are achieved. Under PPP, each party draws its own benefit, proportionate to its interest.

Public-Private Partnerships as a phenomenon and the artefact in the study provides multiple factors that are provided with utmost consideration. Certain processes and types of PPP's within the status quo are presently being implemented within context of certain infrastructure projects in Zamboanga Peninsula. Issues on contract out, mixed capital, privatization and lease franchise projects are some of such example under PPP's that are implemented and practiced. There are mitigating factors considered that most processes are administered yet laws and rules have not been concocted so as to address the processing of Public-Private Partnerships.

Finally, factors that are taken into consideration whether Public-Private Partnership projects could be successful or not depends on numerous internal and external considerations that dominate the framework and ecosystem on the implementation of such infrastructure projects. Internal success factors are taken into account in terms of the implementation of programs or projects on infrastructure development. Contrast flexibility and innovation among parties involved predominantly transpires and is factored in. Liabilities and risks within the bounds of project implementation are inevitably foreseen. In this point of view the transparency and credibility are subjected which pave the way for mutual benefits and achievement of both parties' objectives. In addition, external effects that are under consideration are also recognized as the environment that provides sound and good social and political environment with greater legal grounding and backing. The Public-Private Partnership therefore is guided by a simple belief that government and firms working in meaningful collaboration will deliver mega-projects that have better outcomes than any one party could deliver on their own. The study therefore aimed to evaluate the administrative capability of Local Government Units (LGUs) to enable them to engage in Public-Private Partnership (PPP) for infrastructure development in Zamboanga Peninsula.

\section{TECHNICAL CONTENTS}

The methodologies employed in the study vary primarily on each of problems stated as the focal points of this research. The predominant theme of qualitative narrative research rests upon sub-research instruments for interpretation and analysis. These instruments are clearly and methodically inculcated to provide the researcher a step by step procedural dispensation of the study at hand.

Ethnography is a time-tested research technique that has been popular, especially in the field of anthropology (Bordens and Abbott, 2018). It is also used in sociological and psychological studies of various behaviour systems. It is interesting to note that the interplay of various human behavioural patterns is predominantly a factor in the capabilities of companies, institutions and societies. Moreover, in the examination of capabilities, particularly administrative, plays a critical role in the success of any endeavours of various fields of discipline. The pillars of the study of administrative capability, trussed on leadership, human resource management and financial resource management, takes into consideration the examination of the interaction of such factors that makes or breaks fundamental missions and visions of the Local Government Units in Zamboanga Peninsula on infrastructure development. The non-participants observation as a sub-set of ethnographic research is utilized as the data extraction done is observed, transcribed and analysed that the status- 
quo and the phenomenon on operational procedures in the Local Government Units (LGUs) warrants the data for legitimate examination.

As a whole, the study utilized qualitative design in order to evaluate the administrative capability of Local Government Units (LGUs) for Public-Private Partnership (PPP) towards infrastructure development in Zamboanga Peninsula. The utilization of a narrative research qualification equates a further interpretation of the data gathered. In this case, the data were subjected to analysis using textual presentation and was warranted based upon existing related literatures and related studies. The present systematic implementation in the status quo was presented as to compare and contrast what was written in the documents presented and the actual implementation of each project.

This study made use of primary and secondary sources of data. Primary data were collected from the respondents through in-depth interviews and questionnaire instrumentation. This implies that responses presented were a consolidation of different views, ideas, experiences, and understanding of public-private partnership and the administrative capability of the LGUs to implement projects through this scheme. Moreover, government documents, reports, journals and other articles served as secondary sources of data for the study. This is important so as the integration of the present policies and regulations of Public-Private Partnership and the actual system of operational procedure within the status quo of the research can clearly be seen and analysed.

The research locale of this study were the major cities of Zamboanga Peninsula and the municipalities in the provinces of Sibugay, Zamboanga Del Sur and Zamboanga Del Norte which includes Pagadian City, Dipolog City, Dapitan City and Zamboanga City. The municipalities of Buug, Aurora, Manukan, Titay Sindangan, Lakewood and Tampilisan. These areas in Zamboanga Peninsula were chosen as the research local based on the number of infrastructure projects implemented and on the pipeline for 2017 onwards.

The target respondents of the study are the higher executives or their representatives of the major cities and municipalities of Zamboanga Peninsula. These would include project coordinators, city and municipality engineers. The respondents were chosen based on their roles in infrastructure development in their area of responsibility. The purposive sampling method was employed in this particular study to get the targeted population. Face to face interviews, observations and documentations were the primary method applied for data collection with the appointive local government officials comprising the primary source of data. The documents maintained by the local organization were also used as secondary sources of data.

The findings revealed that the level of administrative capability of the LGUs to implement infrastructure development projects in Zamboanga Peninsula in terms of leadership is relatively high since there were lots of projects being implemented which were materialized through the political will of the local chief executives. Several projects were also in the pipeline for 2017 implementation. The infrastructure projects are being done through RA 9184 and the BAC. The projects are being monitored in several ways which include but not limited to project team together with the inspection team from the City Planning and Engineering Office. Moreover, the project engineer supervises the project on a daily basis and submits monthly report to the City Planning Office and other department concerned. The implemented projects of the participating municipalities are being monitored through monthly inspection by the LGU monitoring team; depending on the Program of Work, three ocular inspections are done to see if specifications are being followed plus the monthly monitoring of the LGU team. During the interviews, the respondents revealed that the internal monitoring and auditing done on infrastructure projects in their own LGU is by COA with regular monitoring by the City Engineer's Office. 
Surprise and random visits are also being done by the appointed internal audit. Other respondents said inspection is also done by the implementing agencies with pictures required before, during and after the completion of the projects together with the representative from the Accounting Department together with the COA serves as the Internal Monitoring and Auditing Team. Despite the introduction of PhilGEPS and the mandate that all public procurement pass through the electronic bulletin system, journalists, watchdogs and other CSOs continue to face significant information availability problems. Compliance with reporting requirements is lacking, the information tracked by government entities is incomplete, and the data that are nominally available are subject to a range of arbitrary bureaucratic and logistical barriers to public use. When the respondents were asked "if they think leadership is an important feature of the administrative capability of the LGU in handling PPP projects?", they answered "Yes, it is very important since the head of the LGU such as the mayor needs to be a visionary who could see way ahead and dream for his constituents and locality; without the political will of the mayor everything will be in chaos. Others said that "no leadership skills from the head of the organization will lead to demoralization which often leads to corruption.”

In terms of financial resource management, the level is also high considering that all projects in the different LGUs followed the necessary guidelines and policies on procurement, prioritization, and full disclosure among others. The Community Social Organizations (CSOs) participate in the thrust towards participatory and transparent governance in terms of budget preparation, assessment, and monitoring of projects. As observed from the protocols employed following standard procedures mandated by law, the efficiency and speed of transactions in terms of management are bureaucratic and systematic. The participants revealed that the public and other CSOs participate in the thrust towards participatory and transparent governance in terms of budget preparation. They emphasized that the public and other CSOs participate from the time the survey is conducted to the consultations with the different stakeholders involved in the project. Further, the participants revealed that the CSOs or their representative sits as member in all special bodies/committees. When the representatives from the four cities were asked if they think the financial resources management capability of their LGUs meet the requirement for the implementation of PPP projects, they answered in the affirmative.

In terms of human resource management, the level is moderate since there were limited trainings conducted to enhance the skills of the personnel to be part of the different infrastructure projects since one of the qualifications in hiring is skills and specialization. As this exist within the system, the contractors have their own personnel to do the projects and the role of the LGU is just to monitor if the specifications and implementation are being followed or made based on the Programs of Work. It is important to consider the human resource facet of certain projects on infrastructure development and implementation for the said resource serves as a foundation for proper implementation of programs and projects within the city's jurisdiction. The allocation of personnel on each position presents itself as an integral part of this ordeal for the specialization, job-fit and job description of each personnel fulfils the necessary implications and roles that play in the application of given infrastructure development project. The creation of this gap within the human resource organization, by not filling the available positions, creates a vacuum within the proper management of the knowledge and skills of each personnel. Since a temporary notion is placed within the minds of contractual personnel, the exploitation of each particular knowledge and skill sets are misappropriated and mismanaged. This disables an acquisition of greater utilization of contractual personnel's fullest potential to contribute in the development and success of the infrastructure development programs in the city. Finally, the upper managerial positions that are granted a regular position in the respective government agency may grow complacent and sedentary in the implementation of such projects. It is profoundly observed, that most government infrastructure development projects may consume insurmountable time in its accomplishment. 
Mitigating circumstances present itself that paper-works and other standard operational protocols provide a consummation of time and effort which can be well estimated through proper management of the human resource and administrative management. In the interviews conducted among participants of the eight municipalities and four cities revealed that "the skills development in employees involved in infrastructure projects includes but not limited to AUTOCAD and enhancement of civil, electrical, mechanical and survey works." Some of the participants also disclosed that "enhancement of other skills such as leadership, management, technical abilities and administrative were included.” Respondents from one of the municipalities said that "personnel or employees to be assigned in the different LGUs projects should be trained in AUTOCAD and GSI."

The problems/constraints/challenges that were encountered by the LGUs in the implementation of the infrastructure projects were limited since there were no PPP projects yet in the participating cities and municipalities. The addition of projects within the pipeline may greatly augment sources for implementation of PPP projects within the Zamboanga Peninsula. Some problems/constraints/challenges in common projects that were encountered by the LGUs in the implementation of the infrastructure projects include the inadequate project preparation, poor project quality at entry, and poor project execution give rise to delays and changes in project scope and cost during implementation that significantly reduced the project value as well as hampered the attainment of project objectives. The most common problems encountered during implementation are related to right-of-way and resettlement issues and institutional arrangement among concerned agencies and/or LGUs which deter the accomplishment of sector goals.

\section{CONCLUSIONS}

Based on the finding, the following conclusions were hereby drawn:

- The level of administrative capability of the LGUs to implement infrastructure development projects in Zamboanga Peninsula in terms of leadership is relatively high since there were lots of projects being implemented which were materialized through the political will of the local chief executives. Leaders in the Local Government Units within Zamboanga Peninsula are satisfactorily adept with policies and procedures on the application of Public-Private Partnerships among the infrastructure development projects within the region. Existing organizational inherent protocols practiced among leaders within the government units greatly influence leadership capabilities in the implementation of projects that are plotted within the pipeline. This proves to be advantageous and at the same time detrimental in the development of said structures for certain procedures are mandated to be implemented based on existing laws and regulations instituted as government and administrative policies. Leaders are aware of the necessary procedures for the implementation that should be undertaken yet attitudinal and societal inherent behaviours are present within the system that creates incidents that prove to be an impediment to its thorough application and implementation. Delegation and bequeathal of certain responsibilities among leaders create a vacuum of misinterpretation and miscommunication among the constituents of the administration.

- 2. The level of administrative capability of the LGUs to implement infrastructure development projects in Zamboanga Peninsula in terms of financial resource management is also high considering that all projects in the different LGUs followed the necessary guidelines and policies on procurement, prioritization, and full disclosure among others. Financial Resources Management among others creates an impact to the system of PPP application within the Zamboanga Peninsula. The bureaucratic system prevalent within the institution and its administrative 
capacity enables the delegation of decision-making processes and allocation of funding to certain chosen projects that are a priority to people or leaders within the hierarchy of the administration. This proves that majority of the decision would come from the upper echelons of the organization and the efficiency and speed of the decisions would be taken into consideration.

- 3. The level of administrative capability of the LGUs to implement infrastructure development projects in Zamboanga Peninsula in terms of Human Resource Management is moderate since there were limited trainings conducted to enhance the skills of the personnel to be part of the different infrastructure projects.

- 4. No major problems that can hinder the Local Government Units (LGUs) both Cities and Municipalities to engage in the Public-Private Partnership (PPP) for infrastructure development projects in Zamboanga Peninsula.

\section{ACKNOWLEDGEMENT}

Sincere thanks and appreciation are extended to Dr. Frede G. Moreno, the Dean of the College of Public Administration and Development Studies of the Western Mindanao State University, Zamboanga City, Philippines, and to Dr. Ma. Carla Ochotorena, Dr. Sarah S. Taupan, Dr. Vivian R. Molina, Dr. Teresita A. Narvaez and Dr. Rosalio D. Tenorio for their invaluable guidance and contributions for the ultimate completion of this research work.

\section{REFERENCES}

1. Agra, A. (2005). Survey of Supreme Court Decisions on Local Autonomy and Local Governments from January 1, 1992 to July 31, 2005. Seminar Handout Ateneo Professional Schools, Makati City.

2. Agranoff, R. (2007). Managing within networks: Adding value to public organization. Washington, DC: Georgetown University Press.

3. Badshah, A. (1998). Good Governance for Environmental Sustainability. UNDP, http://sdnhq.undp.org/pppue.

4. Barlow, J., Roehrich, J. K., Wright, S. (2013). Europe Sees Mixed Results from Public-Private Partnerships for Building and Managing Health Care Facilities and Services. Health Affairs 32 (1): 146-154. Doi: 10.1377/hlthaff.2011.1223. PMID 23297282.

5. Basu, R. (2004). Public Administration: Concepts and Theories. New Delhi, Sterling Publishers Private.

6. Behn, R. (1998). What right do public managers have to lead? , Public Administration Review, Vol. 58 No. 3 pp. 209-24.

7. Bhattacharya, A. K. and Dubey, M. K. (2007). Public people private partnership for sustainable forest development: proceedings of the workshop, contributory articles and relevant acts, rules, and regulations. Indian Institute of Forest Management, New Delhi, Concept Publishing Company.

8. Brewster, C. and Bournois, F. (1991). Human Resource Management: A European Perspective, Personnel Review, Vol. 20 ISS: 6, pp. 4-13.

9. Brown, T. L., Potoski, M. and Van Slyke, D. (2011). Managing public service contracts: Aligning values, institutions and markets. Public Administration Review, 66, $323-331$.

10. Cardona, M. and Punsalan, A. (2008). Government Accounting, 2008 Edition. Manila: GIC Enterprises and Co. pp. 243.

11. Coffey, A., Holbrook B. and Atkinson, P. (1996). Qualitative Data Analysis: Technologies and Representations. Sociological Research Online, vol. 1, no 1, http://www.socresonline.otg.uk/1/1/4.html. 
12. Cuaresma, J. C. and Ilago S. A. (1996). Local Fiscal Administration in the Philippines, Philippines: Local Government Center, College of Public Administration, University of the Philippines and the Public Administration Promotion Centre, German Foundation for International Development.

13. De Guzman, R. P. and Reforma, M. A. (1993). Decentralization towards democratization and development in the Asian Pacific Region. In Tapales, P. D. and Brillantes, A. B. Jr. Eds. 1998. Local Government in the Philippines: A Book of Reading. Vol. 1 Local Government Administration, CLRG and NCPAG, University of the Philippines.

14. Fairholm, M. R. (2004). Different perspectives on the practice of leadership. Public Administration Review, 64 (5).

15. Fleishman, E. A., Mumford, M. D., Zaccaro, S. J., Levin, K. Y., Korotkin, A. L., and Hein, M. B. (1991). Taxonomic efforts in the description of leader behaviour: A synthesis and functional interpretation. Leadership Quarterly, 2, 245-287.

16. Fligstein, N. (2001). Organization: Theoretical Debates and the Scope of Organizational Theory. Department of Sociology, University of California, Berkeley.

17. Flores, M. G. R. (2013). Achieving Sustainable Implementation of Public-Private Partnership Programs: A Comparative Study on the Road Infrastructure Development in the Philippines and South Korea Based on the Infrascope Framework. Unpublished Master's Thesis. KDI School of Public Policy and Management. Republic of Korea.

18. Flyvbjerg, B., Bruzelius, N. and Rothengatter, W. (2003). Megaprojects and Risk: An Anatomy of Ambition, New York: Cambridge University Press.

19. Gatti, S. (2013). Project Finance in Theory and Practice: Designing, Structuring, and Financing Private and Public Projects. Academic Press. ISBN 9780123919465.

20. Garvin, M. (2010). Enabling Development of the Transportation Public-Private Partnership Market in the United States. Journal of Construction Engineering and Management. 136, 402-411.

21. Hilderbrand, M. E. and Grindle, M. S. (1997). Building sustainable capacity in the public sector: what can be done? In M.S. Grindle (ed.), Getting Good Government: capacity building in the public sector of developing countries. Harvard University Press, Harvard: 30-61.

22. Irefin, M. P. and Bwala, D. (2012). Organizational Theories and Analysis: A Feminist Perspective. International Journal of Advancements in Research and Technology, 1(1), 71-97.

23. Javier, A. B. (2010). The Local Economic Development Framework for Local Government Units in the Philippines. Local Governance Support Program for Local Economic Development (LGSP-LED) - Department of Interior and Local Development.

24. Joaquin, Ma. E. (2002). Implementation of the Local Government Code in the Municipality of Muntinlupa, Metro Manila, Prepared for the Ford Foundation and the Local Government Center, 1995, Unpublished manuscript.

25. Johnson, C. E. (2001). Meeting the ethical challenges of leadership. Thousand Oaks, CA: Sage Publishers.

26. Julao, N. O. (2010). Public-Private Infrastructure Advisory Facility (PPIAF). PPP Short Story Competition. Case Study Winner, Washington, DC.

27. Kamoche, K. (1997). Managing Human Resources in Africa: Strategic, Organizational and Epistemological Issues, International Business Review, Vol. 6, pp. 537-558.

28. Kaul, M. (2000). Management Reforms in Government. A review of International Practices and Strategies. Canada. CAPAM.

29. Keenoy, T. (1990). HRM: A Case of the Wolf in Sheep's Clothing? Personnel Review, Vol. 19 ISS: 2, pp. 3- 9. 
30. Kotter, J. P. (1990). A force for change: How Leadership Differs from Management. New York: Free Press.

31. Lavergne, R. and Saxby, J. (2001). Capacity development: vision and implications. Capacity Development Occasional Series, Vol. 6088:0-11. Canadian International Development Agency, Gatineau, Quebec, Canada.

32. Legge, K. (2004). Human Resource Management: Rhetoric and Realities-Anniversary Edition Hamps: Palgrave McMillan.

33. Lemma, A. (2013). Literature Review: Evaluating the Costs and Benefits of centralized PPP units. EPS PEAKS.

34. Li, B., Akintoye, A. and Hardcastle, C. (2001). Risk Analysis and Allocation in Public-Private Partnerships Projects. 17th ARCOM Annual Conference. Salford. Vol. 2, pp. 895-904.

35. Mahmood, Z., Basharat, M. and Bashir, Z. (2012). Review of classical management theories. International Journal of Social Sciences and Education, 2 (1), 512-522.

36. Manasan, R. G. (2005). A Review of Investment Incentives in ASEAN Countries. Philippines Institute of Development Studies. Working paper 08-27, PIDS Manila.

37. Mangahas, J. (2002). Assessment of Capacity Building Needs of Biodiversity Areas Management Board in the Philippines. Department of Environment and Natural Resources and United Nations Development Programme.

38. McQuaid, R. W. (2000). The Theory of Partnership: why have partnerships. In S. P. Osborne (Ed.). Public-Private Partnerships: Theory and practice in international perspective, pp. 9-36. New York: Routeledge.

39. Morgan, P. (2004). Capacity and Capacity Development-Some Strategies. Policy Branch, CIDA was quoted in Ndolamb Ngokwey, Capacity Building in UNICEF Supported Programmes Challenges and Opportunities.

40. Mustafa, A. (1999). Public-Private Partnership: An Alternative Institutional Model for Implementing the Private Finance Initiative in the Provision of Transport Infrastructure. The Journal of Project Finance, Summer, 64-79.

41. Northouse, G. (2007). Leadership theory and practice. $3^{\text {rd }}$ Edition Thousand Oak, London, New Delhi, Sage Publications, Inc.

42. O'Toole, J. (2001). When leadership is an organizational trait. In W. Bennis, G. M. Spreitzer and T. G. Cummings (Eds.). The Future of Leadership (pp.158-176). San Francisco, CA: Jossey-Bass.

43. Padilla, P. L. (1992). Strengthening Local Government Administration and Accelerating Local Development, Philippines: Local Government Center, College of Public Administration, University of the Philippines and the Asia Foundation.

44. Perez, B. and March, J. (2006). Public-Private Partnerships and the Development of Transport Infrastructure: Trends on Both Sides of the Atlantic. First International Conference on Funding Transportation Infrastructure Institute of Public Economics at the University of Alberta, Canada.

45. PPP Manual for LGUs (2012). Understanding PPP Concepts and Framework: Developing Public Private Partnerships in Local Infrastructure and Development Projects, Vol. 1, PPP Center, Quezon City.

46. Pratchett, L. and Wingfield, M. (1996). Petty bureaucracy and woolly-minded liberalism? The changing ethos of local government officers. Public administration, Vol. 74, No. 4, pp. 639-656.

47. PPPP (2008). Primer to Public-Private Partnerships in Infrastructure Development Transport Policy and Development Section, United Nations Economic and Social Commission for Asia and the Pacific (ESCAP).

48. Sajo, T., Santiago, E. V., and Joaquin, Ma. E. (1998). Handbook of Modern Management in Philippine Local Government. Quezon City: Center for Local and Regional Governance and German Foundation for International Development.

49. Smyth, A. and Edkins, J. (2007). Relationship management in the management of PFI/PPP projects in the UK. International Journal of Project Management 25: 232-240. 
50. Soriano, M. C., Steffensen, J., Makayan, E. P. and Nisperos, J. B. (2005). Assessment of non-ERA transfers and other funds for devolved services in the Philippines, unpublished study submitted to the World Bank Office, Manila.

51. Stark, A. (2002). What is New Public Management? Journal of Public Administration Research and Theory: J-PART Vol. 12, No. 1 (Jan., 2002), pp. 137-151.

52. Teicher, J., Alam, Q. and Gramberg, B. V. (2006). Managing trust and relationships in PPPs: Some Australian experiences. International Review of Administrative Sciences 72: 85-100.

53. Wettenhall, $R$. (2003). The rhetoric and reality of public-private partnerships. Public Organization Review, 3 (1), 77-107.

54. Wren, D. A. and Bedeian, A. G. (2004). The evolution of management thought. United State of America: John Wiley \& Sons, Inc.

55. Wright, P. C. and Rudolph, J. J. (1994). HRM Trends in the 1990s: Should Local Government Buy in? International Journal of Public Sector Management, Vol. 7 ISS: 3, pp. 27-43.

56. World Bank (2012). "Public-Private Partnership, Version 1.0, Reference Guide" Washington, D.C., USA.//www.ppiaf.org/sites/ppiaf.org.files/publication/Public-Private-Partnership-Reference-Guide.pdf.

57. World Bank (2007). Public-Private Partnership Units: Lessons for their designs and use in infrastructure.

58. World Bank (1994). Development Report: Infrastructure for development. New York: Oxford University Press.

59. World Bank and the Philippines Government (2004). Workshop on Joint Supervision of Projects Providing Services at the Local Level.

60. Yescombe, E. R. (2007). Public-Private Partnerships: Principles of Policy and Finance. Oxford: Elsevier Finance.

61. Zheng, J., Roehrich, J. K., and Lewis, M. A. (2008). The dynamics of contractual and relational governance: Evidence from long-term public-private procurement arrangements. Journal of Purchasing and Supply Management, 14 (1): 43-54. 